\title{
Investigating the molecular basis of multiple insecticide resistance in a major malaria vector Anopheles funestus (sensu stricto) from Akaka-Remo, Ogun State, Nigeria
}

Seun M. Atoyebi 1,2, Genevieve M. Tchigossou 1,3, Romaric Akoton 1,3, Jacob M. Riveron ${ }^{4,5}$, Helen Irving ${ }^{4}$, Gareth Weedall ${ }^{4,6}$, Eric Tossou ${ }^{1,3}$, Innocent Djegbe ${ }^{1,7}$, Isaac O. Oyewole ${ }^{8}$, Adekunle A. Bakare ${ }^{2}$, Charles S. Wondji ${ }^{4,9}$ and Rousseau Djouaka ${ }^{1 *}$

\begin{abstract}
Background: Understanding the mechanisms used by Anopheles mosquitoes to survive insecticide exposure is key to manage existing insecticide resistance and develop more suitable insecticide-based malaria vector control interventions as well as other alternative integrated tools. To this regard, the molecular basis of permethrin, DDT and dieldrin resistance in Anopheles funestus (sensu stricto) at Akaka-Remo was investigated.

Methods: Bioassays were conducted on 3-5-day-old adult An. funestus (s.s.) mosquitoes for permethrin, DDT and dieldrin susceptibility test. The molecular mechanisms of mosquito resistance to these insecticides were investigated using microarray and reverse transcriptase PCR techniques. The voltage-gated sodium channel region of mosquitoes was also screened for the presence of knockdown resistance mutations ( $k d r$ west and east) by sequencing method.
\end{abstract}

Results: Anopheles funestus (s.s.) population was resistant to permethrin (mortality rate of 68\%), DDT (mortality rate of 10\%) and dieldrin (mortality rate of $8 \%$ ) insecticides. Microarray and RT-PCR analyses revealed the overexpression of glutathione S-transferase genes, cytochrome P450s, esterase, trypsin and cuticle proteins in resistant mosquitoes compared to control. The GSTe2 was the most upregulated detoxification gene in permethrin-resistant $(F C=44.89)$, DDT-resistant $(F C=57.39)$ and dieldrin-resistant $(F C=41.10)$ mosquitoes compared to control population ( $F C=22.34$ ). The cytochrome P450 gene, CYP6P96 was also upregulated in both permethrin- and DDT-resistant mosquitoes. The digestive enzyme, trypsin (hydrolytic processes) and the cuticle proteins (inducing cuticle thickening leading to reduced insecticides penetration) also showed high involvement in insecticide resistance, through their overexpression in resistant mosquitoes compared to control. The $k d r$ east and west were absent in all mosquitoes analysed, suggesting their non-involvement in the observed mosquito resistance.

Conclusions: The upregulation of metabolic genes, especially the GSTe2 and trypsin, as well as the cuticle proteins is driving insecticide resistance of An. funestus (s.s.) population. However, additional molecular analyses, including functional metabolic assays of these genes as well as screening for a possible higher cuticular hydrocarbon and lipid contents, and increased procuticle thickness in resistant mosquitoes are needed to further describe their distinct roles in mosquito resistance.

\footnotetext{
*Correspondence: r.djouaka@cgiar.org

${ }^{1}$ International Institute of Tropical Agriculture, 08 BP 0932, Cotonou, Benin

Full list of author information is available at the end of the article
}

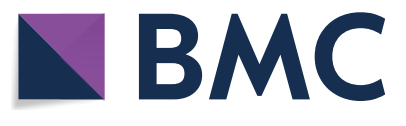

(c) The Author(s) 2020. This article is licensed under a Creative Commons Attribution 4.0 International License, which permits use, sharing, adaptation, distribution and reproduction in any medium or format, as long as you give appropriate credit to the original author(s) and the source, provide a link to the Creative Commons licence, and indicate if changes were made. The images or other third party material in this article are included in the article's Creative Commons licence, unless indicated otherwise in a credit line to the material. If material is not included in the article's Creative Commons licence and your intended use is not permitted by statutory regulation or exceeds the permitted use, you will need to obtain permission directly from the copyright holder. To view a copy of this licence, visit http://creativeco mmons.org/licenses/by/4.0/. The Creative Commons Public Domain Dedication waiver (http://creativecommons.org/publicdomain/ zero/1.0/) applies to the data made available in this article, unless otherwise stated in a credit line to the data. 
Keywords: Anopheles funestus, Permethrin, DDT, Metabolic genes, Insecticide Resistance mechanisms, Nigeria

\section{Background}

A population of Anopheles funestus (sensu stricto) in Nigeria was recently shown to be resistant to different classes of public health insecticides commonly used for malaria vector control [1]. There was a higher concern with permethrin resistance (68\% mortality) at AkakaRemo due to the over-reliance on pyrethroids for insecticide-treated nets (ITNs) and a few indoor residual sprays (IRS) [2]. DDT (10\% mortality) and dieldrin (8\%) resistance reported is also delaying the re-introduction of these cheap insecticides as alternatives to pyrethroids [1]. There is an increasing rate of insecticide resistance of $A n$. funestus (sensu lato) in Africa and resistance has been observed to have spread across different regions [3-5]. One of the main concerns from existing reports is that each population displays its peculiar mechanisms to tolerate insecticides exposure [6-8]. Nevertheless, populations within the same region may share similar resistance mechanisms, which might be a consequence of gene flow across these regions [6].

To date, metabolic-based mechanisms have been the main driver of insecticide resistance in An. funestus (s.l.) [5-8]. Cytochrome P450s (P450s) and glutathione S-transferase (GSTs) are two gene families that are always associated with the mosquito resistance. The P450s such as CYP6P9a/b, CYP6M7, CYP9K1 and $C Y P 6 Z 1$ have various roles they play in pyrethroids resistance [4, 9]. Interestingly, as resistance gets stronger, more $\mathrm{P} 450$ genes are evolving in resistant mosquitoes [4, 8]. Glutathione S-transferases, a phase II detoxification gene family are known to be involved in both permethrin and DDT resistance of An. funestus (s.l.). Several reports have shown that the epsilon class, GSTe2 is a key detoxification gene, which is displayed by its overexpression in permethrin and DDT-resistant mosquitoes [10,11]. In addition to its overexpression, the nucleotide substitution process on position 119 on the gene, thereby changing leucine to phenylalanine has given the GSTe2 a greater advantage to metabolise DDT [11].

Djouaka et al. [1] have already reported the roles of oxidase and high resistant allelic frequency $(\mathrm{f}(\mathrm{R})=77 \%)$ of the L119F-GSTe2 mutation in resistant An. funestus at Akaka-Remo. However, there is a need for thorough molecular-based analyses to further understand the various mechanisms developed by the An. funestus (s.s.) population against insecticides. For these analyses, a genome-wide transcriptional analysis by microarray and the reverse transcriptase polymerase chain reaction (RT-PCR) were conducted to identify the set of detoxification genes associated with DDT and permethrin resistance in the mosquito population. Also, the voltage-gated sodium channel (VGSC) sequence (permethrin and DDT target site) was screened to investigate the presence of knockdown resistance $(k d r)$ mutations (L1014F and L1014S) in wild $\left(\mathrm{F}_{0}\right)$ mosquito species.

\section{Methods}

This is a follow-up study from Djouaka et al. [1]. From the previous study, An. funestus (s.s.) collected were exposed to permethrin, deltamethrin, DDT, dieldrin, bendiocarb and malathion, with bioassay test showing that this mosquito population was resistant to all insecticides tested except for malathion. The $F_{1}$ mosquitoes generated from this previous study were further analysed for their molecular mechanisms of resistance in the present study. Below is a brief methodology on how mosquitoes were collected, and bioassays were conducted, already documented in the previous paper (for details, see Djouaka et al. [1]).

\section{Description of field mosquitoes and the laboratory susceptible strain, FANG}

Female blood-fed adult An. funestus (s.l.) mosquitoes were collected indoors between 6:00 and 10:00 h at Akaka-Remo $\left(6^{\circ} 57^{\prime} \mathrm{N}, 3^{\circ} 43^{\prime} \mathrm{E}\right)$ using electric aspirators. Field mosquito samples were collected from October 2014 to April 2015. After collections, mosquitoes were sorted out by species and the blood-fed were kept into cups until fully gravid. Thereafter, they were forced to lay eggs [12] that were sent via courier to the Liverpool School of Tropical Medicine (LSTM) for rearing into $F_{1}$, insecticide susceptibility tests [13] and molecular analysis. Anopheles funestus (s.l.) were first identified morphologically using standard keys [14] and later identified molecularly [15] to the subspecies level. Hatched eggs were pooled and reared together (temperature of $25-28{ }^{\circ} \mathrm{C}$ and relative humidity of $80 \%$ ) in mineral water, which was renewed every two days to reduce mortality, and the resulting larvae were daily fed with Tetramin ${ }^{\mathrm{TM}}$ baby fish.

For laboratory experiments, mosquito populations used were defined as: (i) permethrin-resistant, also referred to as Rperm: An. funestus that were resistant after exposure to $0.75 \%$ permethrin; (ii) DDT-resistant, also referred to as $\mathrm{R}_{\mathrm{DDT}}$ : An. funestus that were resistant after exposure to $4 \% \mathrm{DDT}$; (iii) unexposed mosquitoes, also referred to 
as Control and represented with the symbol C: An. funestus that were not exposed to any insecticide and used as control samples during bioassay and other analysis; (iv) fully susceptible $A n$. funestus strain, also referred to as FANG or susceptible mosquitoes and represented with the symbol S: FANG mosquitoes are insecticide-susceptible strain of $A n$. funestus, that originated from southern Angola and have been maintained in the laboratory since January 2003 [16, 17].

\section{Bioassays and synergist test with DEM and DEF}

The 3-5-day old $F_{1}$ adult samples obtained from pooled mosquitoes were exposed to permethrin (0.75\%), DDT (4\%) and dieldrin (4\%) to assess the insecticide susceptibility status of An. funestus (s.s.) population. A minimum of $100 \mathrm{~F}_{1}$ mosquito samples were tested for each insecticide according to the WHO guidelines [13]. At least 4 replicates of 25 mosquitoes per tube were exposed to insecticide-impregnated papers (with 2 replicates of 25 mosquitoes exposed to untreated papers as control) for $1 \mathrm{~h}$ and were immediately transferred into clean holding tubes with $10 \%$ sugar solution. Mortality records were taken after $24 \mathrm{~h}$ post-exposure as described by the WHO [13]. Resistant and susceptible mosquitoes generated from bioassays were stored in pools of 10 and 5, respectively at $-80^{\circ} \mathrm{C}$ for molecular analysis [18].

Furthermore, another set of mosquitoes were used for the synergist test to analyse the roles of GSTs and esterase in the observed resistance. Mosquitoes were first exposed to diethyl maleate (DEM) and S,S,S-tributyl phosphorotrithioate (DEF) for $1 \mathrm{~h}$ each and were immediately exposed to either permethrin or DDT for another $1 \mathrm{~h}$ according to the WHO guidelines [13] to evaluate the roles of glutathione $\mathrm{S}$-transferase (DEM) and esterase (DEF) in the observed phenotypic resistance. This mosquito population has been previously exposed to $\mathrm{PBO}$ to evaluate the role of oxidase and results are available in Djouaka et al. [1]. At least 50 mosquitoes were tested, and mortality was recorded $24 \mathrm{~h}$ post-exposure [13].

\section{Microarray}

The genome-wide transcriptional screening was done to identify gene sets that were differentially overexpressed in resistant An. funestus mosquitoes at Akaka-Remo, as a possible mechanism for the observed phenotypic resistance. The Agilent Anopheles funestus chip, $8 \times 60 \mathrm{k}$ (60-mer) designed using the eArray program (Agilent: A-MEXP-2374) was used for the microarray hybridization analysis. This chip contains the $4 \times 44$ array (A-MEXP-2374) [10] plus an additional 15,527 expressed sequence tags (ESTs) generated from a transcriptome sequence analysis of An. funestus [19]. Overall, each array is incorporated with 60-mer probes designed from
8540 ESTs (2 probes for each EST) generated from $A n$. funestus transcriptome 454 sequencing [20], a set of 2850 An. funestus cDNAs from GenBank (2 probes for each EST), a set of $\mathrm{P} 450$ genes (3 probes for each gene) from the $r p 1$ and $r p 2$ QTL BAC sequence [21, 22], and the 13,000 transcripts of the complete An. gambiae genome. Also, all of the $A n$. gambiae detoxification genes present on the An. gambiae detox chip [23] were added to this chip with 3 probes for each gene to explore all possible gene sequences conserved between $A n$. gambiae and $A n$. funestus.

Total RNA was extracted from three batches of a pool of 10 An. funestus (s.s.) mosquitoes in the different populations using Picopure RNA Isolation Kit (Arcturus, Waltham, USA). The quantity and quality of RNA were assessed using NanoDrop ND1000 spectrophotometer (Thermo Fisher Scientific, Waltham, MA, USA) and Bioanalyzer (Agilent, Santa Clara, CA, USA), respectively. The complementary RNA (cRNA) was then amplified from each extracted RNA by labelling resistant samples (R) with cy5 dye and susceptible strain FANG samples (S) with cy3 dye using the Agilent Quick Amp Labeling Kit (two-color) following the manufacturer's protocol. The quality and quantity of the labelled cRNA samples were further assessed as described above before hybridization on the array at $65{ }^{\circ} \mathrm{C}$ for $17 \mathrm{~h}$. In total, five and four hybridizations were done for permethrin and DDT comparisons, respectively, which consist of three (permethrin) and two (DDT) biological replicates, as well as two dye swaps each.

\section{Reverse transcriptase PCR analysis}

The expression pattern of known resistant-associated genes was evaluated in resistant samples compared to the unexposed control using the RT-PCR. This analysis was performed for some selected metabolic genes that were either identified in the microarray analysis or previously associated with permethrin and DDT resistance in An. funestus mosquitoes [8, 11, 20, 21]. Metabolic genes analysed are glutathione $S$-transferase family (GSTe2, GSTd3, GSTd1-5); cytochrome P450 genes (СYР6P9a, СYР6P9b, СYР6Р4a, CYР6P4b, CYР6M7, CYP6AA1, CYP4C27, CYP9K1); aldehyde oxidase (Ald $o x i$ ) and trypsin. This experiment was conducted using three batches of a pool of 10 resistant $R_{\text {perm }}$ and $R_{D D T}$, unexposed control and FANG mosquitoes [10]. Briefly, RNA extracted from each pool was used to synthesize cDNA using Superscript III (Invitrogen, Waltham, USA) with oligodT20 and RNase $\mathrm{H}$ according to the manufacturer's instructions. The RT-PCR amplification was performed using the MX 3005P (Agilent, California, USA) system: first, five-serial dilutions of the synthesize cDNA samples were done and analysed to 
generate PCR efficiency and quantitative differences between samples, where a standard curve was generated for each gene. The following PCR mix was used for a single reaction in this experiment: $10 \mu \mathrm{l} \mathrm{SyBr} \mathrm{Green;}$ $0.6 \mu \mathrm{l}$ of both the forward and reverse $10 \mathrm{mM}$ primers

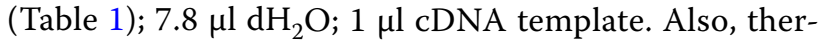
mal condition parameters used are: 1 cycle at $90{ }^{\circ} \mathrm{C}$ for 3 min for initial denaturation, 40 cycles of $95^{\circ} \mathrm{C}$ for $10 \mathrm{~s}$ and $60{ }^{\circ} \mathrm{C}$ for $10 \mathrm{~s}$ for the amplification (final denaturation, annealing, extension and fluorescence read), and 1 cycle of $95^{\circ} \mathrm{C}$ for $1 \mathrm{~min}, 55^{\circ} \mathrm{C}$ for $30 \mathrm{~s}$ and $95^{\circ} \mathrm{C}$ for $30 \mathrm{~s}$ for dissociation/melting. The primers used for target genes are attached (Table 1).

\section{Partial sequencing of the VGSC gene, target site of permethrin and DDT}

A fragment spanning a portion of the voltage-gated sodium channel gene (VGSC), containing the 1014 codon associated with insecticide resistance in $A n$. gambiae was amplified in ten wild female An. funestus mosquitoes from Akaka-Remo using the KdrFunR2 primer (5'-CCG AAA TTT GAC AAA AGC AAA$\left.3^{\prime}\right)[6,18,24]$. The amplicons were purified using the Qiaquick purification kit (Qiagen, Hilden, Germany) before subjecting to sequencing.

\section{Data analysis}

After hybridization and scanning in the microarray experiment, data obtained were analyzed using the Genespring GX 13.0 software: differentially expressed genes were selected at a statistical significance level of $P \leq 0.05$ with Benjamini-Hochberg correction for multiple testing of a cut-off of 2 fold change (FC), except for some exemptions (comparisons of DDT-S and Perm-C) that differentially expressed genes were only identified at no correction multiple testing but still with $\mathrm{t}$-test against zero and a cut-off of $1.5 \mathrm{FC}$ at $P \leq 0.05$.

For the reverse transcriptase PCR analysis, resulting data for each gene was normalized with housekeeping genes: ribosomal protein S7 (RSP7; AGAP010592), and actin 5C (AGAP000651) before calculating the relative expression level and FC of each target gene in resistant and control relative to the susceptible according to the 2- $\Delta \Delta C Q$ method, incorporating the PCR efficiency [25]. For partial sequencing of the VGSC region, BioEdit software was used to manually trace all sequence set to detect polymorphic positions and for ClustalW alignment [26], while haplotype construction/polymorphic analysis was done with DnaSP v5.10 [27]. Sequence data generated from the Akaka-Remo population were compared to sequence sets previously obtained from Kpome [28] and Pahou [24] in southern Benin, and Gounougou [5] in northern Cameroon. In addition, a NeighbourJoining (NJ) tree was generated using MEG 6.06 after the level of Kst of pairwise genetic differentiation between populations was determined with Dnasp v5.10. Also, Maximum Likelihood (ML) phylogenetic tree was constructed for the VGSC haplotypes in different sample populations with Mega 6.06 using the best constructing model [29].

\section{Results}

The GSTs and esterase were implicated in pyrethroid and DDT resistance of An. funestus (s.s.)

All the 96 blood-fed An. funestus (s.l.) that oviposited and subjected to the forced egg-laying were morphologically and molecularly identified as $A n$. funestus (s.s.) as reported in the previous study [1]. Also, the $F_{1}$ mosquitoes generated and tested for

Table 1 List of primers used for the reverse transcriptase PCR

\begin{tabular}{|c|c|c|}
\hline Gene primer & Forward $\left(5^{\prime}-3^{\prime}\right)$ & Reverse $\left(5^{\prime}-3^{\prime}\right)$ \\
\hline CYP6M7 & CCAGATACTGAAAGAGAGCCTTCG & CAAGCACTGTCTTCGTACCG \\
\hline CYP6P9a & CAGCGCGTACACCAGATTGTGTAA & TCACAATTTTTCCACCTTCAAGTAATTACCCGC \\
\hline CYP6P9b & CAGCGCGTACACCAGATTGTGTAA & TTACACCTTTTCTACCTTCAAGTAATTACCCGC \\
\hline CYP6Р4a & AACTCGTATTCGACCCCAAA & CGTTTCCATGGAATTACATTTTCTG \\
\hline CYP6P4b & AACTCGTATTCGACCCCAAA & ACAATCATTATACCACACATCTGAC \\
\hline CYP6AA4 & CATCTGGCTGAATGGCACTA & TCAACAATGCCATCAAATCG \\
\hline CYP9K1 & AGGGCTTCTGGATACGGTTC & CGTACGGTTCGGTTTTGATT \\
\hline Trypsin & GGCCACAACCTCAAAGTCTC & CGACAGAAATCAGTCGTTAGTACG \\
\hline GSTe2 & GTTTGAAGCAGTTGCCATACTACGAGG & TCAAGCTTTAGCATTTTCCTCCTTTTTGGC \\
\hline GSTd3 & CACGGCCAGTCCTCTTTTAG & AAGCTTCTTCGCCACCAGTA \\
\hline GSTd1-5 & TGGAGAAATACGGCAAGGAC & CTTGGCGAAGATTTGTGGAT \\
\hline Aldehyde oxidase & GCTCTGAACATTGCACCTCA & TGGTGTCGAACGATTGTGTT \\
\hline RSP7 & GTGTTCGGTTCCAAGGTGAT & TCCGAGTTCATTTCCAGCTC \\
\hline Actin & TTAAACCCAAAAGCCAATCG & ACCGGATGCATACAGTGACA \\
\hline
\end{tabular}


insecticide susceptibility were resistant to permethrin $(68 \pm 5.64 \%)$, DDT $(10 \pm 2.66 \%)$ and dieldrin $(8 \pm 3.24 \%)$ as reported in Djouaka et al. [1]. In addition to the role of oxidase in the resistance of this mosquito population as documented in Djouaka et al. [1], esterases and GSTs also showed their involvement in the observed permethrin and DDT resistance in the present study (Fig. 1). Anopheles funestus (s.s.) showed a $100 \%$ mortality with permethrin when pre-exposed to both DEM and DEF, suggesting the implication of GSTs and esterase in permethrin resistance. Similarly, the pre-exposure of mosquitoes to DEM and DEF, and then to DDT resulted in mortalities of $71 \%$ and $82 \%$, respectively, which equally suggests the role of GSTs and esterase in DDT resistance.

\section{Microarray revealed that upregulation of metabolic genes} plays a crucial role in permethrin and DDT resistance of $A n$. funestus (s.s.)

Differentially expressed transcripts were identified in the comparisons of permethrin/DDT resistant samples to controls. Three mosquito populations were analysed for permethrin resistance: Rperm; unexposed control; susceptible FANG, and two populations for DDT resistance: $\mathrm{R}_{\mathrm{DDT}}$ and susceptible FANG. For comparison analysis, a total of 1536 (798 overexpressed) transcripts were differentially expressed in Rperm-S, 1467 (230 overexpressed) differentially expressed transcripts in Rperm-C, while the $\mathrm{R}_{\mathrm{DDT}}{ }^{-} \mathrm{S}$ comparison produced 664 (299 overexpressed) transcripts, as well as 2473 (1093 overexpressed) transcripts in C-S. There was no $\mathrm{R}_{\mathrm{DDT}}-\mathrm{C}$ cross analysis due to the high DDT resistance recorded.
Gene expression profiling showed an association between the upregulation of multiple metabolic genes and permethrin resistance of An. funestus (s.s.)

Microarray data analysed with genespring, GX 13.0 software successfully identified commonly expressed transcripts in the different comparisons. There was only one common transcript (Afun000762) overexpressed in all the three comparisons, Rperm-S, C-S and Rperm-C with fold changes (FC) of 5.19, 3.83 and 2.53, respectively (Fig. 2a, Table 2), with no detoxification gene commonly overexpressed in these three comparisons.

\section{Common transcripts overexpressed in Rperm-S and C-S}

There were 445 common transcripts overexpressed in this comparison out of 973 differentially expressed transcripts. Only two of these transcripts are associated with resistance: the cuticle proteins (5 transcripts) and carboxylesterase. Cuticle proteins had higher overexpression: CD578215.1 (Rperm-S, FC $=17.81 ; \quad \mathrm{C}-\mathrm{S}, \quad \mathrm{FC}=43.40), \quad \mathrm{CD} 578215.1$ (Rperm-S, $\quad \mathrm{FC}=14.75 ; \quad \mathrm{C}-\mathrm{S}, \quad \mathrm{FC}=36.74), \quad$ Afun010482 (Rperm-S, FC =18; C-S, FC=65.91), CD577507.1 (Rperm$\mathrm{S}, \mathrm{FC}=3.56$; $\mathrm{C}-\mathrm{S}, \mathrm{FC}=5.87$ ) and Afun013390 (Rperm-S, $\mathrm{FC}=4.11 ; \mathrm{C}-\mathrm{S}, \mathrm{FC}=3.47$ ), while carboxylesterase on the other hand produced a relatively lower fold change with Afun015266 (Rperm-S, FC=2.88; C-S, FC=2.88) (Table 2).

\section{Common transcripts overexpressed in Rperm-S}

This comparison produced the GSTu2 $(\mathrm{FC}=4.25)$, a member of the GSTs family. The other resistanceassociated genes overexpressed are glucosyl glucuronosyl transferases (3 transcripts) with fold changes of 2.25, 2.44 and 2.10 and chymotrypsin 1 (Afun010134: $\mathrm{FC}=4.75)$. An electron transport trans-membrane protein, cytochrome b561 (Afun008617; $\mathrm{FC}=2.20$ ) was also overexpressed.
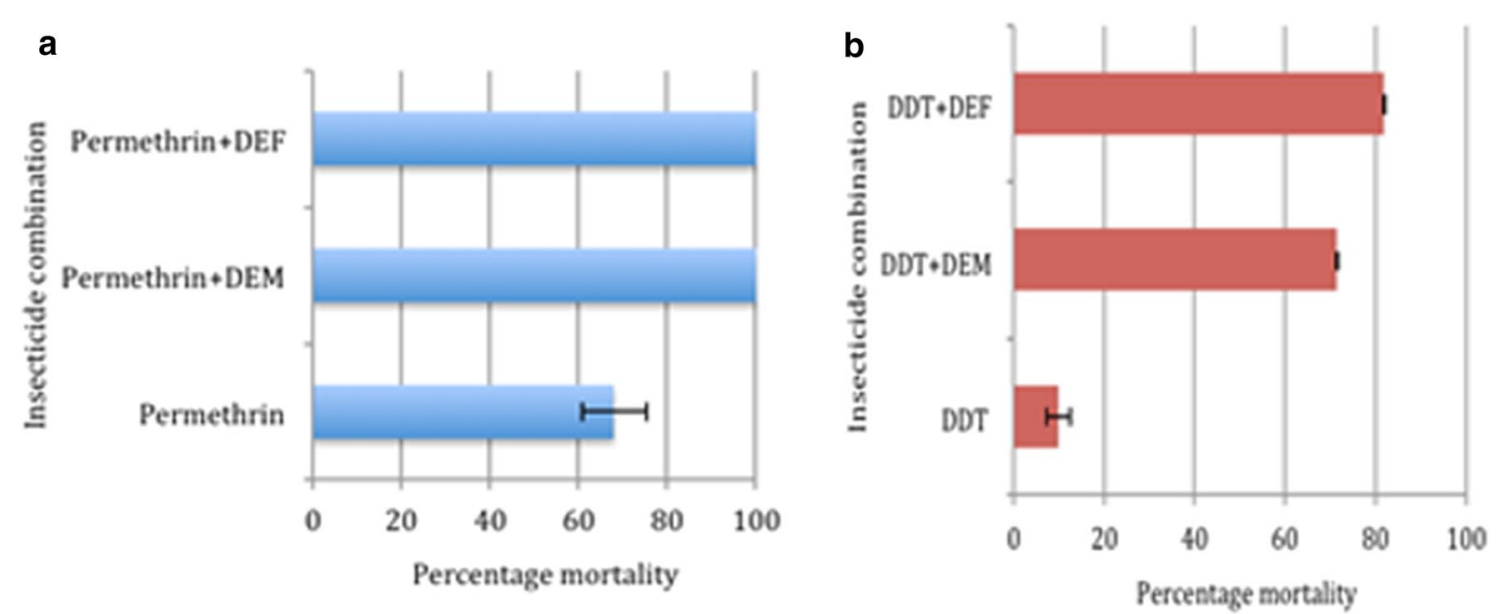

Fig. 1 DEM and DEF synergist assessment of permethrin and DDT insecticides 


\section{Common transcripts overexpressed in C-S}

Four transcripts, CYP9J3 $(\mathrm{FC}=2.3), \quad$ CYP6P9a $(\mathrm{FC}=2.92), \quad C Y P 6 P 9 b \quad(\mathrm{FC}=14.48)$ and $C Y P 6 A A 4$ $(\mathrm{FC}=3.49)$ of the cytochrome $\mathrm{P} 450$ monooxygenase were overexpressed in this comparison (Table 2). The $C Y P 6 P 9 b$ had the highest overexpression while the other duplicated gene, CYP6P9a that has been implicated in permethrin resistance of different An. funestus populations was also overexpressed. Other resistanceassociated genes in this group are the short-chain dehydrogenase (AGAP001405-RA_2R, $F C=2.42$ ), carboxylesterase (COEAE6O, $\mathrm{FC}=2.15$ ), 3 transcripts of trypsin (AGAP011431-RA_3L, FC $=2.02$; CD578079.1, $\mathrm{FC}=2.38$ and $\mathrm{CD} 578079.1 \mathrm{FC}=2.98)$, cytochrome $\mathrm{C}$ (BU039010.1, $\mathrm{FC}=2.13$ ) and 2 transcripts of the cuticle proteins (Afun008525, FC $=20.18$ and CD577507.1, $\mathrm{FC}=2.32)$.

\section{Common transcripts overexpressed in Rperm-C}

Two transcripts of the cytochrome $\mathrm{P} 450$ genes were overexpressed in the Rperm- $C$ comparison. The CYP6P9a $(\mathrm{FC}=2.92)$ and CYP6P2 $(\mathrm{FC}=2.47)$ were identified to be playing a role in the detoxification of permethrin. The GST gene (AGAP004164-RC, $\mathrm{FC}=2.09)$ was also overexpressed as well as the esterase family, esterase fe4 (Afun014849, $\mathrm{FC}=2.03$ ) in this comparison.

\section{Genes associated with permethrin resistance using RT-PCR technique}

The GSTe2 gene was upregulated in permethrin-resistant mosquitoes $(\mathrm{FC}=44.89)$ compared to the unexposed control $(F C=22.34)$ (Fig. 3a) using the RT-PCR. Both GSTd3 and GSTd1-5 were also upregulated in resistant mosquitoes compared to control but with lower folds [GSTd3: $\mathrm{FC}=4.27$ (resistant) vs 1.75 (control) and GSTd1-5: $\mathrm{FC}=7.1$ (resistant) vs 4.3 (control)] compared to the GSTe2. Some cytochrome P450 genes, like the CYP6P4a $[\mathrm{FC}=2.98$ (resistant) vs 1.72 (control)] and slightly in $C Y P 9 K 1$ [FC $=2.66$ vs 2.44] were upregulated in Rperm over the unexposed control mosquitoes. Trypsin was also overexpressed in the resistant $(\mathrm{FC}=2.42)$ compared to the control $(0.31)$.

\section{Gene expression profiling also revealed} that the upregulation of multiple metabolic genes drives DDT resistance of An. funestus (s.s.)

There was no detoxification gene overexpressed in these different comparisons $\left(\mathrm{R}_{\mathrm{DDT}}-\mathrm{S}, \mathrm{C}-\mathrm{S}\right.$ and Rperm-S; $\mathrm{R}_{\mathrm{DDT}} \mathrm{S}$ and $\mathrm{C}-\mathrm{S} ; \mathrm{R}_{\mathrm{DDT}}-\mathrm{S}$ and Rperm-S; Rperm-S and C-S). However, there were few resistant-associated transcripts (cytochrome P450s, GSTs, carboxylesterase, glucosyl glucuronosyl transferases, chymotrypsin, short-chain dehydrogenase, trypsin and cuticle proteins) identified in other comparisons. There was only one P450 transcript (CYP6AK1, $\mathrm{FC}=1.69$ ) overexpressed in $\mathrm{R}_{\mathrm{DDT}}-\mathrm{S}$ (Table 3). The other transcripts upregulated in this comparison were cuticle protein genes (AGAP009480-RA_3R, $\mathrm{FC}=1.94$; AGAP003382RA_Cuticular, $\mathrm{FC}=1.84$ ), chymotrypsin 1, (combined_c3760, FC=2.13), short-chain dehydrogenase (CD577943.1, $\mathrm{FC}=1.72)$ and the nucleotide binding protein 2 (AGAP011997-RA_3L, FC=1.64). Transcripts of cytochrome P450s, GSTs are among the detoxification genes that were overexpressed in the C-S comparison. There were four transcripts of the P450 genes in the C-S comparison: CYP9J3 $(\mathrm{FC}=2.30)$; CYP4AA4 $\quad(\mathrm{FC}=3.49) ; \quad C Y P 6 P 9 b \quad(\mathrm{FC}=14.48) \quad$ and AGAP012291-RA_3L, $(\mathrm{FC}=2.42)$. There was also an overexpression of the GSTS1 $(\mathrm{FC}=2)$, a member of the sigma GSTs. The other detoxification genes overexpressed here were the short-chain dehydrogenase,
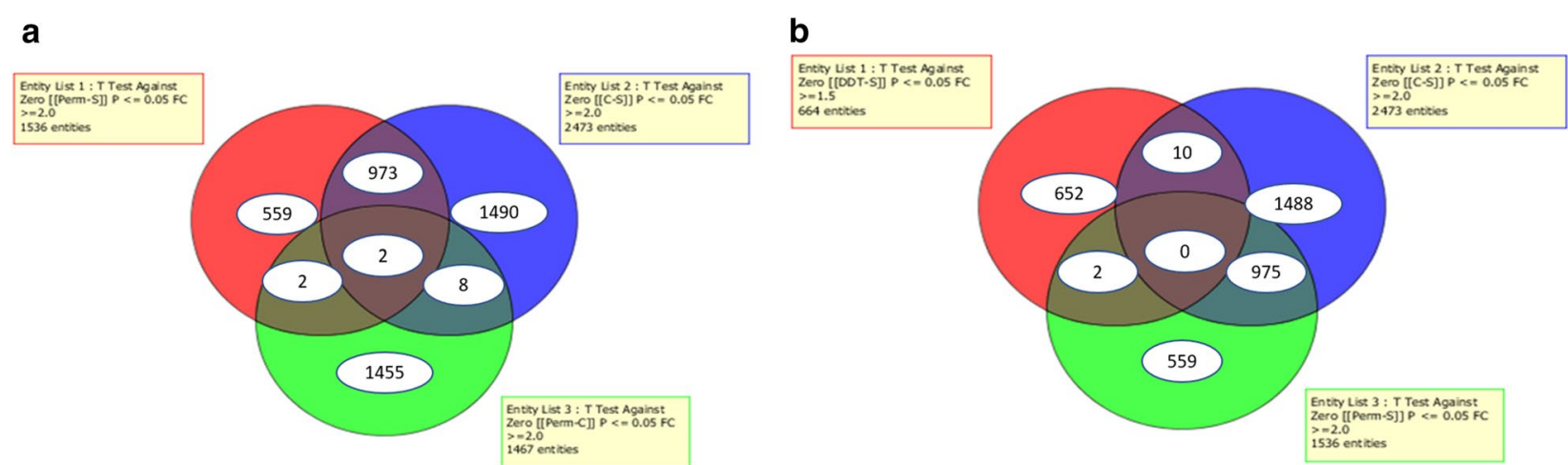

Fig. 2 a Transcripts differentially expressed in permethrin resistance. b Transcripts differentially expressed in the cross-analysis of DDT and permethrin resistance. Venn diagram displays the number of significantly $(P \leq 0.05)$ up or down-regulated transcripts, and the commonly expressed transcripts ( $F C \geq 2$ ) in each comparison 
Table 2 Detoxification genes upregulated in Rperm-S, C-S and Rperm-C

\begin{tabular}{|c|c|c|c|c|c|c|c|}
\hline $\mathrm{S} / \mathrm{N}$ & Transcript name & Gene name & Rperm-S FC & C-SFC & Rperm-C FC & Ortholog in An. gambiae & Description \\
\hline 1 & CUST_762_PI426302897 & Afun000762 & 5.19 & 3.83 & 2.53 & AGAP006733 & THO complex subunit 4 \\
\hline 2 & CUST_2376_PI406199772 & CD578215.1 & 17.81 & 43.40 & & & Cuticle protein \\
\hline 3 & CUST_2375_PI406199772 & CD578215.1 & 14.75 & 36.74 & & & Cuticle protein \\
\hline 4 & CUST_15266_PI426302897 & Afun015266 & 2.44 & 2.88 & & AGAP010911-PA & Carboxylesterase \\
\hline 5 & CUST_10482_PI426302897 & Afun010482 & 18.00 & 65.91 & & AGAP008449-PA & Cuticle protein \\
\hline 6 & CUST_3752_PI406199772 & CD577507.1 & 3.56 & 5.87 & & & Cuticle protein \\
\hline 7 & CUST_13390_PI426302897 & Afun013390 & 4.11 & 3.47 & & AGAP000344-PB & Cuticular protein rr-1 \\
\hline 8 & CUST_15708_PI406199769 & Combined_c8336 & 2.25 & & & & $\begin{array}{l}\text { Glucosyl glucuronosyl } \\
\text { transferases }\end{array}$ \\
\hline 9 & CUST_7571_PI426302897 & Afun007571 & 2.44 & & & AGAP007920-PA & $\begin{array}{l}\text { Glucosyl glucuronosyl } \\
\text { transferases }\end{array}$ \\
\hline 10 & CUST_15707_PI406199769 & Combined_c8336 & 2.10 & & & & $\begin{array}{l}\text { Glucosyl glucuronosyl } \\
\text { transferases }\end{array}$ \\
\hline 11 & CUST_8617_PI426302897 & Afun008617 & 2.02 & & & AGAP005222-PB & Cytochrome b561 \\
\hline 12 & CUST_15122_PI426302897 & Afun015122 (GSTU2) & 4.25 & & & AGAP003257-PA & Glutathione S-transferase gst \\
\hline 13 & CUST_10134_PI426302897 & Afun010134 & 4.75 & & & AGAP006711-PA & Chymotrypsin 1 \\
\hline 14 & CUST_1378_PI406199798 & AGAP001405-RA_2R & & 2.42 & & AGAP001405-RA_2R & Short-chain dehydrogenase \\
\hline 15 & CUST_484_PI406199788 & gb-СYР9J3 & & 2.30 & & & Cytochrome p450 \\
\hline 16 & CUST_5277_PI406199769 & Combined_c2672 & & 2.20 & & & Cuticular protein 97eb \\
\hline 17 & CUST_36_PI406199775 & COEAE6O & & 2.15 & & AGAP002863-PA & Carboxylesterase \\
\hline 18 & CUST_5_PI406199775 & CYP6AA4 & & 3.49 & & & Cytochrome p450 \\
\hline 19 & CUST_11060_PI406199798 & AGAP011431-RA_3L & & 2.02 & & AGAP011431-RA_3L & Trypsin 5 \\
\hline 20 & CUST_3941_PI406199772 & CD577405.1 (GSTS1) & & 2.00 & & & Glutathione-S-transferase \\
\hline 21 & CUST_4873_PI406199772 & BU039010.1 & & 2.13 & & & Cytochrome c \\
\hline 22 & CUST_8525_PI426302897 & Afun008525 & & 20.18 & & AGAP000047-PA & Cuticle protein rr-1 \\
\hline 23 & CUST_3943_PI406199772 & CD577404.1 & & 2.38 & & & Glutathione S-transferase \\
\hline 24 & CUST_3751_PI406199772 & CD577507.1 & & 2.32 & & & Cuticle protein \\
\hline 25 & CUST_13027_PI406199798 & AGAP012291-RA_3L & & 2.42 & & AGAP012291-RA_3L & Cytochrome p450 \\
\hline 26 & CUST_2644_PI406199772 & CD578079.1 & & 2.70 & & & Trypsin \\
\hline 27 & CUST_2643_PI406199772 & CD578079.1 & & 2.98 & & & Trypsin \\
\hline 28 & CUST_10994_PI426302897 & Afun010994 (CYP6P9b) & & 14.48 & & AGAP002867-PA & Cytochrome p450 \\
\hline 29 & CUST_2814_PI406199769 & $\begin{array}{l}\text { AGAP004164- } \\
\text { RC_glutatathione-S- } \\
\text { transferase }\end{array}$ & & & 2.09 & $\begin{array}{l}\text { AGAP004164-RC_gluta- } \\
\text { tathione-S-transferase }\end{array}$ & Glutathione-S-transferase \\
\hline 30 & CUST_2245_PI406199798 & CYP6P2 & & & 2.47 & & Cytochrome p450 \\
\hline 31 & CUST_4637_PI406199798 & Afun014849 & & & 2.03 & AGAP011507-PA & Esterase fe4 \\
\hline 32 & CUST_10523_PI406199798 & CYP6Р9a & & & 2.92 & & Cytochrome p450 \\
\hline
\end{tabular}

Abbreviation: $\mathrm{FC}$, fold change

AGAP001405-RA_2R $\quad(\mathrm{FC}=2.42), \quad$ carboxylesterase, COEAE6O $(\mathrm{FC}=2.15)$, three transcripts of cuticle proteins (combined_c2672, $\mathrm{FC}=2.2 ;$ Afun008525, $\mathrm{FC}=20.18 ; C D 577507.1, \mathrm{FC}=2.32)$ and three transcripts of trypsin (AGAP011431-RA_3L, $\mathrm{FC}=2.02$; $C D 578079.1, \quad \mathrm{FC}=2.7 ; C D 578079.1, \mathrm{FC}=2.98)$. The cross-analysis between Rperm-S and $\mathrm{R}_{\mathrm{DDT}^{-}} \mathrm{S}$ comparison, which was conducted to identify potential crossresistance genes involved in both DDT and permethrin resistance did not produce any transcript (Fig. 2b, Table 3). However, it produced three transcripts of glucosyl glucuronosyl transferases with fold changes of 2.25 (combined_c8336), 2.44 (Afun007571) and 2.1 (combined_c8336) for the Rperm-S comparison. Also, there was an overexpression of GSTu2 $(\mathrm{FC}=4.25)$, the transmembrane protein, cytochrome b561 $(\mathrm{FC}=2.02)$ and the digestive enzyme, chemotrypsin $1(\mathrm{FC}=4.75)$.

\section{Genes associated with DDT resistance using RT-PCR technique}

The GSTe2 also had the highest expression level in mosquitoes resistant to DDT, producing a fold change 

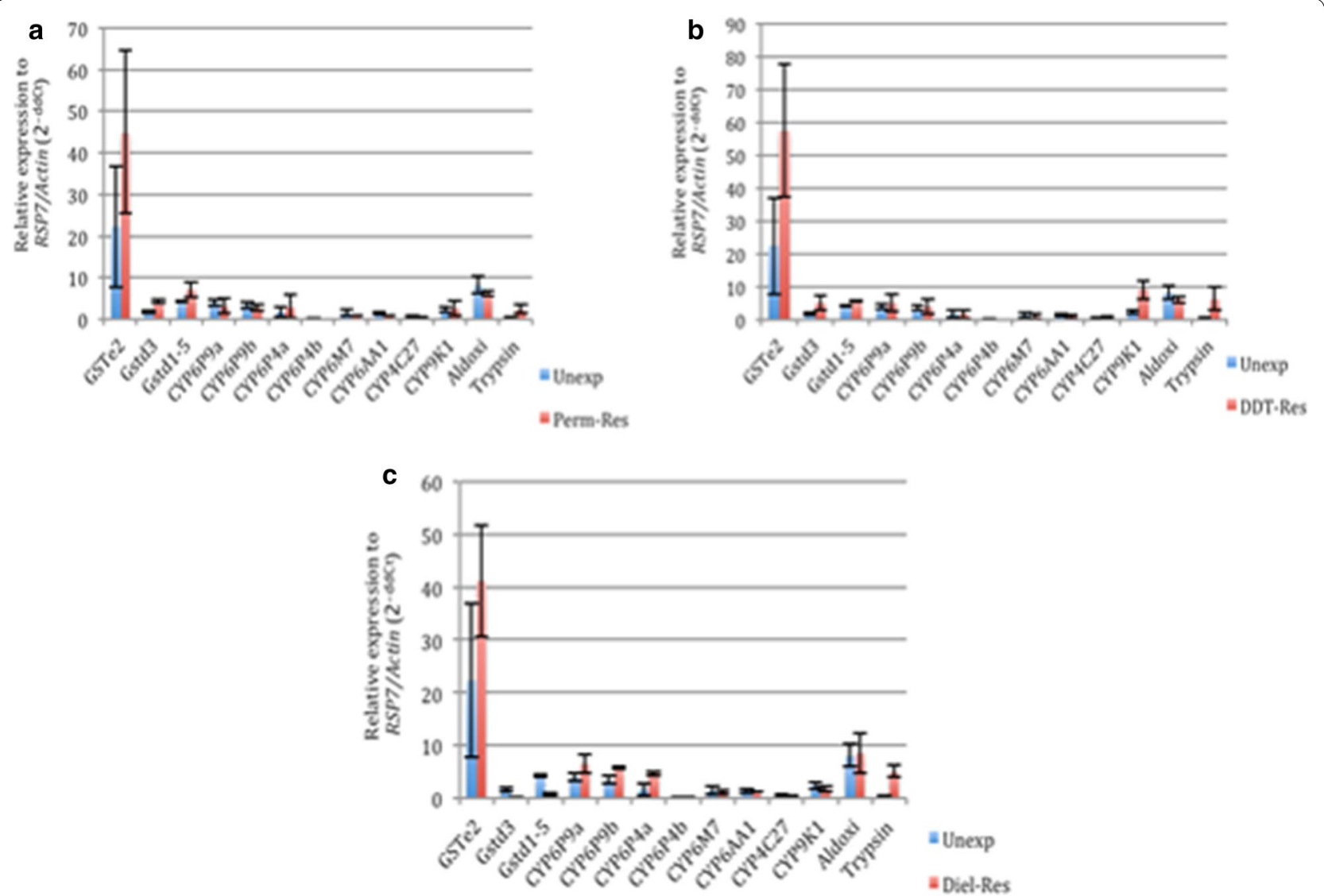

Fig. 3 Gene expression analysis of selected candidate genes in An. funestus that are resistant to DDT (a), permethrin (b) and dieldrin (c) using the RT-PCR. Abbreviations: Unexp, unexposed/control population; perm-Res, permethrin-resistant population; DDT-Res, DDT-resistant population; Diel-Res, dieldrin-resistant population

of 57.39 in DDT-resistant $v s \mathrm{FC}=22.34$ in unexposed control mosquitoes (Fig. 3b). Also, GSTd3 expression $(\mathrm{FC}=5.1)$ was almost 3 -fold higher in DDT-resistant mosquitoes compared to the control $(\mathrm{FC}=1.75)$, while the expression of GSTd1-5 in DDT-resistant mosquitoes $(\mathrm{FC}=5.51)$ was just a little more than 1-fold compared to the control $(\mathrm{FC}=4.3)$. The two duplicates $(C Y P 6 P 9 a$ and $C Y P 6 P 9 b)$ cytochrome P450 genes were both overexpressed in the DDT-resistant mosquitoes compared to the unexposed control (Fig. 4b). However, expression was higher in CYP6P9a $(\mathrm{FC}=5.19)$ than $C Y P 6 P 9 b$ $(\mathrm{FC}=3.91)$. The $C Y P 4 C 27$ expression was also slightly higher in the resistant $(F C=0.92)$ compared to the control $(\mathrm{FC}=0.65)$. The expression of CYP9K1 was the highest $(\mathrm{FC}=9.05)$ compared to the unexposed control $(\mathrm{FC}=2.44)$ in all of the cytochrome $\mathrm{P} 450$ genes analysed. Trypsin expression was also highly overexpressed in DDT-resistant $(\mathrm{FC}=6.21)$ compared to the unexposed mosquitoes $(\mathrm{FC}=0.31)$.

\section{Genes associated with dieldrin resistance using RT-PCR technique}

Glutathione S-transferase genes, cytochrome P450 genes, aldehyde oxidase and trypsin were all upregulated in the dieldrin-resistant mosquitoes (Fig. 3c). The GSTe2 expression was almost 2-fold higher in dieldrin-resistant samples $(F C=41.1)$ compared to the unexposed control $(F C=22.34)$. Both the GSTd3 and GSTd1-5 genes were downregulated in the dieldrin-resistant mosquitoes compared to the control [GSTd3: $\mathrm{FC}=0.28$ (resistant) vs 1.75 (control); GSTd1-5: $\mathrm{FC}=0.78$ (resistant) vs 4.30 (control)], whereas both CYP6P9a and CYP6P9b were overexpressed in dieldrin-resistant samples compared to control. As observed in the DDT-resistant samples, CYP6P9a $(\mathrm{FC}=6.51)$ expression was relatively higher than $C Y P 6 P 9 b(\mathrm{FC}=5.71)$. Another $\mathrm{P} 450$ gene duplicate, $C Y P 6 P 4 a$ and $C Y P 6 P 4 b$ were overexpressed in dieldrinresistant mosquitoes compared to control samples. The expression of CYP6P4a was higher in dieldrin-resistant $(\mathrm{FC}=4.75)$ compared to control $(\mathrm{FC}=1.72)$ mosquitoes. Aldehyde oxidase was slightly overexpressed in 
Table 3 Detoxification genes upregulated in $\mathrm{R}_{\mathrm{DDT}}-\mathrm{S}$, Rperm-S and C-S

\begin{tabular}{|c|c|c|c|c|c|c|c|}
\hline $\mathrm{S} / \mathrm{N}$ & Transcript name & Gene name & $\mathrm{R}_{\mathrm{DDT}-\mathrm{S}} \mathrm{FC}$ & C-S FC & Rperm-S FC & Ortholog in An. gambiae & Description \\
\hline 1 & CUST_421_PI406199788 & gb-CYP6AK1 & 1.69 & & & & Cytochrome P450 \\
\hline 2 & CUST_7149_PI406199798 & AGAP009480-RA_3R & 1.94 & & & AGAP009480-RA_3R & Cuticle protein \\
\hline 3 & CUST_4284_PI406199798 & $\begin{array}{l}\text { AGAP003382-RA_Cuticu- } \\
\text { lar }\end{array}$ & 1.82 & & & $\begin{array}{l}\text { AGAP003382-RA_Cuticu- } \\
\text { lar }\end{array}$ & Cuticle protein \\
\hline 4 & CUST_7428_PI406199769 & Combined_c3760 & 2.13 & & & & Chymotrypsin 1 \\
\hline 5 & CUST_2913_PI406199772 & CD577943.1 & 1.72 & & & & Short-chain dehydrogenase \\
\hline 6 & $\begin{array}{l}\text { CUST_13242_ } \\
\text { PI406199798 }\end{array}$ & AGAP011997-RA_3L & 1.64 & & & AGAP011997-RA_3L & $\begin{array}{l}\text { Nucleotide binding protein } \\
2\end{array}$ \\
\hline 7 & CUST_1378_PI406199798 & AGAP001405-RA_2R & & 2.42 & & AGAP001405-RA_2R & Short-chain dehydrogenase \\
\hline 8 & CUST_484_PI406199788 & gb-СYP9J3 & & 2.30 & & & Cytochrome p450 \\
\hline 9 & CUST_5277_PI406199769 & Combined_c2672 & & 2.20 & & & Cuticular protein 97eb \\
\hline 10 & CUST_36_PI406199775 & COEAE6O & & 2.15 & & AGAP002863-PA & Carboxylesterase \\
\hline 11 & CUST_5_PI406199775 & CYP6AA4 & & 3.49 & & & Cytochrome p450 \\
\hline 12 & $\begin{array}{l}\text { CUST_11060_ } \\
\text { PI406199798 }\end{array}$ & AGAP011431-RA_3L & & 2.02 & & AGAP011431-RA_3L & Trypsin 5 \\
\hline 13 & CUST_3941_PI406199772 & CD577405.1 (GSTS1) & & 2.00 & & & Glutathione S-transferase \\
\hline 14 & CUST_8525_PI426302897 & Afun008525 & & 20.18 & & AGAP000047-PA & Cuticle protein rr-1 family \\
\hline 15 & CUST_3943_PI406199772 & CD577404.1 & & 2.38 & & & Glutathione S-transferase \\
\hline 16 & CUST_3751_PI406199772 & CD577507.1 & & 2.32 & & & Cuticle protein \\
\hline 17 & $\begin{array}{l}\text { CUST_13027_- } \\
\text { PI406199798 }\end{array}$ & AGAP012291-RA_3L & & 2.42 & & AGAP012291-RA_3L & Cytochrome p450 \\
\hline 18 & CUST_2644_PI406199772 & CD578079.1 & & 2.70 & & & Trypsin \\
\hline 19 & CUST_2643_PI406199772 & CD578079.1 & & 2.98 & & & Trypsin \\
\hline 20 & $\begin{array}{l}\text { CUST_10994_ } \\
\text { PI426302897 }\end{array}$ & Afun010994 (CYP6P9b) & & 14.48 & & AGAP002867-PA & Cytochrome p450 \\
\hline 21 & $\begin{array}{l}\text { CUST_15708_- } \\
\text { PI406199769 }\end{array}$ & Combined_c8336 & & & 2.25 & & $\begin{array}{l}\text { Glucosyl glucuronosyl } \\
\text { transferases }\end{array}$ \\
\hline 22 & CUST_7571_PI426302897 & Afun007571 & & & 2.44 & AGAP007920-PA & $\begin{array}{l}\text { Glucosyl glucuronosyl } \\
\text { transferases }\end{array}$ \\
\hline 23 & $\begin{array}{l}\text { CUST_15707_- } \\
\text { PI406199769 }\end{array}$ & Combined_c8336 & & & 2.10 & & $\begin{array}{l}\text { Glucosyl glucuronosyl } \\
\text { transferases }\end{array}$ \\
\hline 24 & CUST_8617_PI426302897 & Cytochrome b561 & & & 2.02 & AGAP005222-PB & Cytochrome b561 \\
\hline 25 & $\begin{array}{l}\text { CUST_15122__ } \\
\text { PI426302897 }\end{array}$ & Afun015122 (GSTU2) & & & 4.25 & AGAP003257-PA & $\begin{array}{l}\text { Glutathione-S-transferase } \\
\text { gst }\end{array}$ \\
\hline 26 & $\begin{array}{l}\text { CUST_10134_ } \\
\text { PI426302897 }\end{array}$ & Afun010134 & & & 4.75 & AGAP006711-PA & Chymotrypsin 1 \\
\hline
\end{tabular}

Abbreviation: $\mathrm{FC}$, fold change

dieldrin-resistant samples $(\mathrm{FC}=8.58)$ compared to the unexposed samples $(\mathrm{FC}=8.12)$ while trypsin expression was higher in dieldrin-resistant mosquitoes $(\mathrm{FC}=5.14)$ compared to control $(\mathrm{FC}=0.31)$.

Partial sequencing of the VGSC region showed that the $k d r$ mutation is not involved in the insecticide resistance of $A n$. funestus (s.s.) population

The portion (924 bp) of the VGSC gene spanning intron 19 and the entire exon 20 (207 bp) located on domain II at segment 6 was successfully amplified (PCR) and sequenced in a total of 11 An. funestus (s.s.) mosquitoes collected from Akaka-Remo. Both L1014F (-TTA- to
-TTT-) and L1014S (-TTA- to -TCA-) $k d r$ mutations that are common to An. gambiae in West and East Africa, respectively, were absent in the sequence analysis. Further analysis with 907-bp sequences obtained and aligned from five individual mosquitoes in this study detected 20 polymorphic sites (887 monomorphic sites) and 8 haplotypes (Fig. 4a, Table 4). Genetic differentiation of this mosquito population analysed using the NJ and ML trees was compared to An. funestus (s.s.) populations from Benin and Cameroon. Analysis using the NJ tree with respect to geographical distance revealed a similar genetic constitution with the Cameroon population but a higher differentiation than Benin populations (Fig. 4b, Table 4). Also, there was 


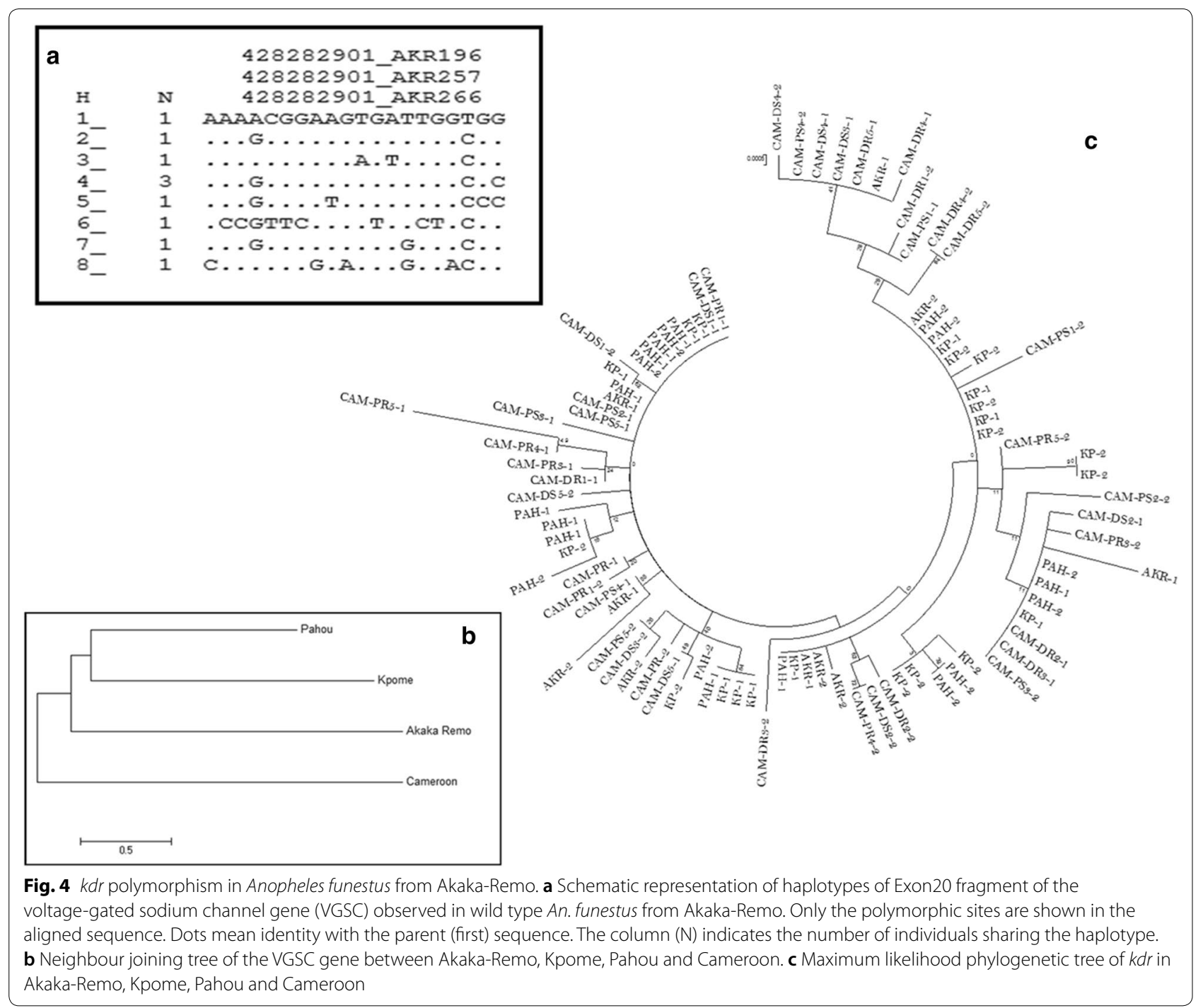

no correlation in the VGSC polymorphisms of the different mosquito populations, which was shown by the lack of clustering of mosquito samples from the same locality in the ML tree (Fig. 4c). The absence of correlation was further supported by the fact that polymorphism did not result into any amino acid change as well as the estimates of Tajima D and $\mathrm{Fu}$ and $\mathrm{Li} \mathrm{D*}$ statistics, which were not statistically significant (Table 4).

\section{Discussion}

Consistent monitoring of insecticide resistance of malaria vectors through the provision of evidencebased information is key to tackle the insecticide resistance challenges facing malaria elimination in Africa. Understanding the mechanisms of insecticide resistance is imperative to improve insecticide-based resistance management strategies. Therefore, providing the molecular basis of permethrin, DDT and dieldrin resistance in Anopheles funestus (s.s.), a major malaria vector in Nigeria will fill an important knowledge gap in the quest to fight malaria in the country. This study has successfully shown that metabolic enzymes are playing vital roles in insecticide resistance of An. funestus (s.s.) at AkakaRemo. This was observed through the overexpression of several detoxification genes, especially the GSTe2 and trypsin. Cuticular resistance was also highly implicated in the resistant mosquito population through the overexpression of cuticle proteins in resistant mosquitoes.

\section{The upregulation of multiple metabolic genes is vital} for permethrin resistance in An. funestus (s.s.)

This study conducted for the first time on this mosquito population revealed that cytochrome $\mathrm{P} 450$ genes 
are slightly involved in the permethrin resistance of this mosquito population. However, it has clearly been previously shown in other An. funestus (s.s.) populations through metabolism assay [30] that $C Y P 6 P 9 a$ can metabolize both type I and type II pyrethroids. The CYP6P9a and $C Y P 6 P 9 b$ duplicates have been associated with pyrethroid resistance in An. funestus (s.s.) across Africa; cases of resistant Fumoz strain [21], Uganda population [6], in Malawi and Mozambique [10] and also in the Chikwawa district of Malawi [4]. The fact that CYP6P9a was only upregulated in Rperm-C comparison in this study could suggest that it might not represent the best possible candidate gene for permethrin resistance of this mosquito population. However, its role in the resistance of this mosquito population is illustrious. The CYP6P4a, CYP6P2, CYP6AA4 and CYP9J3 are the other potential $\mathrm{P} 450$ genes that could be playing a role in permethrin resistance of this mosquito population. In our previous study, the synergist test with $\mathrm{PBO}$ gave a $100 \%$ recovery of susceptibility as against $68 \%$ mortality with only permethrin exposure [1]. This present study has also shown the full involvement of esterase and GSTs in permethrin resistance, with a record of $100 \%$ recovery from susceptibility when each of DEM and DEF was combined with permethrin. This observation highlights the comprehensive roles of oxidase, esterase and GSTs in pyrethroid resistance.

The roles of epsilon (GSTe2) and delta (GSTd3 and GSTd1-5) GST gene families in permethrin resistance were also clearly displayed. The reason for the absence of these key resistance-associated genes in microarray and its presence in qPCR could simply be as a result of biases in dyes used in microarray experiments [31] and crosshybridization or non-specific binding of labelled targets to array probes as pointed out earlier [32]. But the fact that specific primers with the RT-PCR experiment could amplify the GSTe2, GSTd3 and GSTd1-5 genes in permethrin-resistant samples showed their contributions to permethrin resistance of this mosquito population.

The GSTe 2 is a key detoxification gene associated with pyrethroid resistance in An. funestus populations. This is not only because of its elevated expression in An. funestus when exposed to pyrethroids [10] but also its capability to metabolize more pyrethroids after undergoing genetic modifications [11]. Elevated GSTe2 expression has previously been implicated in mosquito resistance by acting as a pyrethroid-binding protein and sequestering the insecticide [33] or by protecting mosquitoes against oxidative stress and lipid peroxidation induced by pyrethroid exposure [34]. Also, a partial knockdown of an ortholog GSTe2 in Ae. aegypti led to increasing pyrethroids (deltamethrin) mortality, which also linked GSTe2 with deltamethrin resistance in this species [35].

Carboxylesterases also showed a great involvement as well as trypsin, indicating that a myriad of several metabolic enzymes is triggered in resistant An. funestus (s.s.) population that empowers mosquitoes to survive permethrin exposure. Overall, our findings suggest that the GSTe 2 could be playing a great role in insecticide resistance due to its expression level, but the key observation from the pattern of gene expression is that the observed resistance is powered by multiple detoxification processes. The other genes with lower expressions, nevertheless, would have played their own distinct and significant roles to achieve such a high level of insecticide resistance. Some of these metabolic proteins (cytochrome P450, carboxylesterase, trypsin) being a phase I machinery are very important first-line defense enzymes that help in the hydrolysis of target insecticides for the phase II detoxification proteins (GSTs and glucosyl glucuronosyl transferases) to further process phase I metabolites for transport and excretion from the mosquito's body system. All these, however, need further investigation to examine the distinct role of each gene in resistance.

\section{DDT resistance of An. funestus (s.s.) is driven}

\section{by the upregulation of multiple metabolic genes}

The elevated expressions of $G S T_{S} 1$ and $G S T_{U} 2$ suggest their contributions to DDT resistance. The $G S T_{S} 1$ had earlier been shown to be associated with insecticide tolerance in mosquitoes. The sigma family of GST in insects possess a proline/alanine-rich $\mathrm{N}$-terminal extension that helps to aid attachment to the flight muscle [36], which make them structurally effective for metabolism. In addition, GSTs show low-level activities with the typical GST

Table 4 Genetic parameters of VGSC of Anopheles funestus from Akaka-Remo compared to Benin and Cameroon populations

\begin{tabular}{|c|c|c|c|c|c|c|c|c|c|c|}
\hline Locality & $N(2 n)$ & $S$ & $\mathrm{Pi}(\pi)$ & K & h & hd & Syn & Non-syn & $D$ & $D^{*}$ \\
\hline Akaka-Remo & 10 & 20 & 0.00524 & 4.75556 & 8 & 0.933 & 0 & 0 & $-1.54^{\mathrm{ns}}$ & $-1.81^{\mathrm{ns}}$ \\
\hline Kpome & 22 & 12 & 0.00351 & 2.93939 & 12 & 0.909 & 0 & 0 & $-0.37^{\mathrm{ns}}$ & $-0.32^{\text {ns }}$ \\
\hline Pahou & 20 & 10 & 0.0026 & 2.17895 & 12 & 0.905 & 0 & 0 & $-0.79^{n s}$ & $-0.96^{\mathrm{ns}}$ \\
\hline Cameroon & 40 & 37 & 0.00514 & 4.30128 & 29 & 0.977 & 2 & 3 & $-1.81^{\mathrm{ns}}$ & $-2.75^{\mathrm{ns}}$ \\
\hline
\end{tabular}

Abbreviations: $2 \mathrm{n}$, number of sequences; $\mathrm{S}$, number of polymorphic sites; $\pi$, nucleotide diversity; $\mathrm{k}$, average number of nucleotide difference; $\mathrm{h}$, number of haplotypes; hd, haplotype diversity; syn, synonymous; Non-syn, non-synonymous; D, Tajima's statistics; D*, Fu and Li's statistics; ns, not significant 
substrates, and have high affinity for the lipid peroxidation product 4-hydroxynonenal [37]. As a result, sigma GST duplicates might also play important roles in eliminating the by-products of oxidative stress [38]. Furthermore, the GSTu2 is yet to be classified into a definite family of GST but it has been shown to share similar phylogeny with the epsilon and delta families of GST $[39,40]$, which could suggest its role in DDT resistance.

The role of GSTe2 in DDT resistance is obvious, considering the difference in expression that was recorded in DDT-resistant mosquitoes $(\mathrm{FC}=57.39)$ against the control population $(\mathrm{FC}=22.34)$ with the RT-PCR analysis. The role of GSTe2 in DDT resistance of An. funestus (s.s.) has been previously documented $[1,3,11]$. Its elevated expression has been key to its capacity to confer resistance in this major malaria vector [11, 28]. The L119FGSTe2 mutation, which has now become very common in different resistant An. funestus populations in Africa $[1,3,11]$ is known to be strengthening the observed phenotypic DDT resistance. Generally, a mosquito carrying this mutation would have an enlarged DDT-binding site, which helps to increase DDT access and metabolism [11]. Leucine (CTT) transformation to phenylalanine (TTT) on position 119 of GSTe2 gene is predominant and almost getting fixed in An. funestus at Akaka-Remo [1]. So, with mutant GSTe 2 dominating the mosquito population, the mosquito would have expressed mainly mutant GSTe 2 enzyme. It is, therefore, possible that the overexpression of GSTe2 may have been influenced by the high L119F mutation in the mosquito population. However, it is necessary to conduct further investigations to fully establish this possible relationship.

The delta family of the GSTs, GSTd3 and GSTd1-5 could also be offering vital metabolic contributions to DDT resistance of this mosquito population due to their higher expressions in resistant compared to control mosquitoes. The P450 genes (CYP6P9a/b, CYP9K1, CYP6AK1, CYP4C27, CYP9J3, CYP6AA4 and CYP6P4a) also had elevated expressions in DDT-resistant samples compared to the control population but because they have been reported to lack the capacity to metabolise DDT [10], their roles in DDT resistance becomes trivial, although not to be neglected. The digestive enzyme, trypsin could also be playing some certain hydrolytic roles in DDT resistance, which will be clearer with more investigations.

\section{Dieldrin resistance of An. funestus (s.s.) was also driven by the upregulation of multiple metabolic genes}

The GSTe2 was observed to be the most overexpressed genes in RT-PCR analysis, suggesting its crucial involvement in dieldrin resistance. Also, the elevated expression recorded with P450 genes (CYP6P9a/b and CYP6P4a), aldehyde oxidase and trypsin highlight their diverse roles in observed dieldrin resistance. Recently, there was a report of a possible target site resistance mechanism through the high frequency of A296S-RDL mutation in An. funestus (s.s.) from Akaka-Remo [1]. Overall, it is possible that this mosquito population engage both target site and metabolic mechanisms to withstand the lethal dose (4\%) of dieldrin. It is therefore important to conduct further experiments to validate this observation.

\section{The upregulation of cuticle proteins potentially reduced the penetration of insecticide molecules into An. funestus (s.s.), contributing to high insecticide resistance}

The observed permethrin and DDT resistance in the An. funestus (s.s.) population was not only driven by detoxifying enzymes but also by cuticular resistance. Cuticle proteins had the highest expression level with the microarray experiments, suggesting their prominent roles in both permethrin and DDT resistance. However, the overexpression of these proteins in unexposed mosquitoes could be the consequence of the high resistance in the mosquito population. This implies that cuticle-based resistance, through the thickening of the mosquito cuticle may be a very important resistance mechanism in $A n$. funestus (s.s.) population. However, further experiments to determine the specific cuticle proteins and the extent of their impact on insecticide resistance of malaria vectors should be considered. It will also be important to measure the cuticle thickness of resistant mosquitoes as against the susceptible ones to further describe the role of mosquito cuticles in resistance [41, 42].

Nkya et al. [43] highlighted the contributions of other factors, such as anthropogenic and industrial chemical xenobiotics as well as microbial compositions resident in mosquito breeding site, to mosquito resistance. It may also be important to investigate the roles of chemical xenobiotics, especially the common ones that mosquito larvae interact with during feeding and breeding in their breeding sites, and to also explore the contribution of microbiota to Anopheles mosquitoes' resistance; this information will help to further manage and holistically strategize on proper and the most suitable insecticide resistance management tools.

\section{Insecticide resistance of $A n$. funestus (s.s.) population is not driven by $k d r$ mutations}

The knockdown resistance mutation is unlikely to be playing a part in the insecticide resistance observed in the $A n$. funestus population. Both L1014F and L1014S mutations that are common to An. gambiae in West and East Africa were absent in all the mosquitoes analysed, as the case of other An. funestus populations in Africa [5, 6, 8, 24, 28]. The VGSC polymorphisms observed could be as a result of evolution through mutation, genetic drift, migration 
or natural selection in the mosquito population. These genetic processes could lead to different genome constitution of An. funestus in the same population, and consequently could help some mosquitoes to survive insecticide exposure. It is appeasing that the diversity of nucleotide sequence observed might not eventually affect the genetic determinant in this mosquito species. However, the potential role of $k d r(\mathrm{~L} 1014 \mathrm{~F} / \mathrm{S})$ in insecticide resistance of $A n$. funestus group should be monitored since genetic polymorphism in this mosquito species is always high and it could also help to detect other potential resistance-associated mutations $[5,6]$.

\section{Conclusions}

This study, which is, to our knowledge, the first to depict the molecular basis of An. funestus (s.s.) in Nigeria, highlights the vital role of GSTe2 in permethrin, DDT and dieldrin resistance. The roles played by the cytochrome P450s were also depicted in the multiple metabolic strategies adopted by this mosquito population. In reality, the P450 genes including the carboxylesterase would have acted on toxic insecticides and make them water-soluble before activating the phase II genes (GSTe2) to completely render the resulting metabolites harmless. However, further investigations including functional assays will help to ascertain the definite roles of these genes in permethrin and DDT resistance. Reduced insecticide penetration into the mosquito through cuticle thickening could also be in operation and contributed greatly to permethrin and DDT resistance of the An. funestus population, which also requires further validation through identifying specific cuticle proteins playing this role in resistant mosquitoes. The resistance mechanisms identified in this mosquito species seem to be peculiar to this mosquito population, so there is need to focus investigations of An. funestus populations per region for suitable improvements of insecticide-based malaria control interventions. Exploring other factors that could potentially contribute to insecticide resistance development in mosquito vectors is also very important at this point that insecticide-resistant mosquitoes are rapidly spreading in Africa.

\footnotetext{
Abbreviations

GST: glutathione S-transferase; DDT: dichlorodiphenyltrichloroethane; ITNs: insecticide-treated nets; IRS: indoor residual spraying; P450: cytochrome P450 genes; VGSC: voltage-gated sodium channel; kdr: knockdown resistance; RT-PCR: reverse transcriptase polymerase chain reactions; LSTM: Liverpool School of Tropical Medicine; DEF: S,S,S-tributylphosphorotrithioate; DEM: diethyl maleate; ESTs: expressed sequence tags; DNA: deoxyribonucleic acid; cDNA: complementary deoxyribonucleic acid; RNA: ribonucleic acid; Rperm: permethrin-resistant; $\mathrm{R}_{\mathrm{DDT}}$ : DDT-resistant; C: control; FANG/S: fully susceptible strain of An. funestus mosquito; FC: fold change; Ald oxi: aldehyde oxidase; CRNA: complementary ribonucleic acid; NJ: Neighbour-Joining; ML: Maximum Likelihood; PBO: piperonyl butoxide.
}

\section{Acknowledgements}

We appreciate the residents of Akaka-Remo and the staff/management of the community health centre for their selfless support during fieldwork, especially MrTunde that helped with mosquito collection throughout the study. We thank Claude Gande and Murielle Soglo for their technical involvements in the study. We also acknowledge Bernard Bett, Jo Lines, Jeff Waage of the Fp5-A4NH and Nafomon Sogoba of the Faculté de Médecine et d'Odontostomatologie (FMOS), Bamako, Mali. for their support.

\section{Authors' contributions}

RD and CSW designed the study. SMA, RA, ET and ID collected mosquito samples. $1 O$ assisted in the identification of study site and mosquito collections. SMA, HI and GT performed microarray, qRT-PCR and sequencing assays. GW assisted with the design of primers used for sequencing. SMA and GT analyzed data with the guidance of GW, JR and CSW. JR and AAB gave advise on the study design and contributed to the implementation of activities. SMA wrote while RD, AAB and CSW reviewed the manuscript. All authors read and approved the final manuscript.

\section{Funding}

This work was mainly funded with the Wellcome Trust grants (Ref: 099864/Z/12/Z and 214201/Z/18/Z) awarded to RD and the Wellcome Trust Senior Research Fellowship in Biomedical Sciences awarded to CSW $(101893 / Z / 13 / Z)$. It also received support from the World Health OrganizationTropical Diseases Research (WHO-TDR) grant (B20388) and the Fp5-A4NH programme of the CGIAR. Wellcome Trust, WHO and A4NH/CGIAR did not play a role in the design of the study, collection, analysis and interpretation of data as well as the writing of the manuscript.

\section{Availability of data and materials}

The datasets supporting the findings herein are included in the article. The DNA data have been deposited in the National Center for Biotechnology Information (NCBI) with the following accession numbers: MT731748, MT731749, MT731750, MT731751, MT731752.

\section{Ethics approval and consent to participate}

Not applicable.

\section{Consent for publication}

Not applicable.

\section{Competing interests}

The authors declare that they have no competing interests.

\section{Author details}

${ }^{1}$ International Institute of Tropical Agriculture, 08 BP 0932, Cotonou, Benin. ${ }^{2}$ Cell Biology \& Genetics Unit, Department of Zoology, University of Ibadan, Ibadan, Nigeria. ${ }^{3}$ University of Abomey Calavi, BP 526, Cotonou, Benin. ${ }^{4}$ Liverpool School of Tropical Medicine, Pembroke Place, Liverpool L3 5QA, UK. ${ }^{5}$ Insecticide Bioscience Department, Syngenta, Toulouse, UK. ${ }^{6}$ Liverpool John Moores University, Liverpool L3 3AF, UK. ${ }^{7}$ National University of Sciences, Technologies, Engineering and Mathematics, Ecole Normale Supérieure de Natitingou, BP 123, Natitingou, Benin. ${ }^{8}$ Biology Department, Babcock University, Ilisan Remo, Ogun State, Nigeria. ${ }^{9}$ Centre for Research in Infectious Diseases (CRID), Yaounde, Cameroon.

Received: 11 March 2020 Accepted: 6 August 2020

Published online: 18 August 2020

\section{References}

1. Djouaka RJ, Atoyebi SM, Tchigossou GM, Riveron JM, Irving H, Akoton R, et al. Evidence of a multiple insecticide resistance in the malaria vector Anopheles funestus in South West Nigeria. Malar J. 2016;15:565.

2. WHO. World malaria report; 2016. Geneva: World Health Organization; 2016. https://www.who.int/malaria/media/world-malaria-report-2016/ en/.

3. Djouaka R, Riveron JM, Yessoufou A, Tchigossou G, Akoton R, Irving H, et al. Multiple insecticide resistance in an infected population of the malaria vector Anopheles funestus in Benin. Parasit Vectors. 2016;9:453. 
4. Ibrahim SS, Ndula M, Riveron JM, Irving H, Wondji CS. The P450 CYP6Z1 confers carbamate/pyrethroid cross- resistance in a major African malaria vector beside a novel carbamate-insensitive N485I acetylcholinesterase-1 mutation. Mol Ecol. 2016;25:3436-52.

5. Menze BD, Riveron JM, Ibrahim SS, Irving H, Antonio-Nkondjio C, AwonoAmbene $\mathrm{PH}$, et al. Multiple insecticide resistance in the malaria vector Anopheles funestus from northern Cameroon is mediated by metabolic resistance alongside potential target site insensitivity mutations. PLoS ONE. 2016;11:e0163261.

6. Mulamba C, Riveron JM, Ibrahim SS, Irving H, Barnes KG, Mukwaya LG, et al. Widespread pyrethroid and DDT resistance in the major malaria vector Anopheles funestus in East Africa is driven by metabolic resistance mechanisms. PLoS ONE. 2014;9:e110058.

7. Riveron JM, Chiumia M, Menze BD, Barnes KG, Irving H, Ibrahim SS, et al. Rise of multiple insecticide resistance in Anopheles funestus in Malawi: a major concern for malaria vector control. Malar J. 2015;14:344.

8. Samb B, Konate L, Irving H, Riveron JM, Dia I, Faye O, et al. Investigating molecular basis of lambda-cyhalothrin resistance in an Anopheles funestus population from Senegal. Parasit Vectors. 2016;9:449.

9. Riveron JM, Ibrahim SS, Mulamba C, Djouaka R, Irving H, Wondji MJ, et al. Genome-wide transcription and functional analyses reveal heterogeneous molecular mechanisms driving pyrethroids resistance in the major malaria vector Anopheles funestus across Africa. G3 Genes Genom Genet. 2017;7:1819-32

10. Riveron JM, Irving H, Ndula M, Barnes KG, Ibrahim SS, Paine MJl, et al. Directionally selected cytochrome P450 alleles are driving the spread of pyrethroid resistance in the major malaria vector Anopheles funestus. Proc Natl Acad Sci USA. 2013;1 10:252-7.

11. Riveron JM, Yunta C, Ibrahim SS, Djouaka R, Irving H, Menze BD, et al. A single mutation in the GSTe2 gene allows tracking of metabolically based insecticide resistance in a major malaria vector. Genome Biol. 2014;15:R27.

12. Morgan JC, Irving H, Okedi LM, Steven A, Wondji CS. Pyrethroid resistance in an Anopheles funestus population from uganda. PLoS One. 2010:5:e11872.

13. WHO. Test procedures for insecticide resistance monitoring in malaria vector mosquitoes: second edition. Global malaria program. Geneva: World Health Organization; 2016.

14. Gillies MT, Coetzee M. A supplement to the Anophelinae of Africa South of the Sahara. Publ South African Inst Med Res. 1987;55:1-143.

15. Koekemoer LL, Kamau L, Hunt RH, Coetzee M. A cocktail polymerase chain reaction assay to identify members of the Anopheles funestus (Diptera: Culicidae) group. Am J Trop Med Hyg. 2002;66:804-11.

16. Oliver SV, Kaiser ML, Wood OR, Coetzee M, Rowland M, Brooke BD. Evaluation of the pyrrole insecticide chlorfenapyr against pyrethroid resistant and susceptible Anopheles funestus (Diptera: Culicidae). Trop Med Int Heal. 2010;15:127-31.

17. Lo TM, Coetzee M. Marked biological differences between insecticide resistant and susceptible strains of Anopheles funestus infected with the murine parasite Plasmodium berghei. Parasit Vectors. 2013;6:1.

18. Cuamba N, Morgan JC, Irving H, Steven A, Wondji CS. High level of pyrethroid resistance in an Anopheles funestus population of the chokwe district in mozambique. PLoS ONE. 2010;5:e11010.

19. Crawford JE, Guelbeogo WM, Sanou A, Traoré A, Vernick KD, Sagnon N, et al. De novo transcriptome sequencing in Anopheles funestus using illumina RNA-seq technology. PLoS ONE. 2010;5:e14202.

20. Gregory R, Darby AC, Irving H, Coulibaly MB, Hughes M, Koekemoer LL, et al. A de novo expression profiling of Anopheles funestus, malaria vector in Africa, using 454 pyrosequencing. PLoS ONE. 2011;6:e17418.

21. Wondji CS, Irving H, Morgan J, Lobo NF, Collins FH, Hunt RH, et al. Two duplicated $\mathrm{P} 450$ genes are associated with pyrethroid resistance in Anopheles funestus, a major malaria vector. Genome Res. 2009;19:452-9.

22. Irving H, Riveron JM, Ibrahim S, Lobo NF, Wondji CS, Ibrahim SS, et al. Positional cloning of rpl2 QTL associates the P450 genes CYP6Z1, CYP6Z3 and CYPGM7 with pyrethroid resistance in the malaria vector Anopheles funestus. Heredity. 2012;109:383-92.

23. David J-P, Strode C, Vontas J, Nikou D, Vaughan A, Pignatelli PM, et al. The Anopheles gambiae detoxification chip: a highly specific microarray to study metabolic-based insecticide resistance in malaria vectors. Proc Natl Acad Sci USA. 2005;102:4080-4.
24. Djouaka R, Irving H, Tukur Z, Wondji CS. Exploring mechanisms of multiple insecticide resistance in a population of the malaria vector Anopheles funestus in Benin. PLoS ONE. 2011;6:e27760.

25. Schmittgen TD, Livak KJ. Analyzing real-time PCR data by the comparative CT method. Nat Protoc. 2008:3:1101-8.

26. Thompson JD, Higgins DG, Gibson TJ. CLUSTAL W: Improving the sensitivity of progressive multiple sequence alignment through sequence weighting, position-specific gap penalties and weight matrix choice. Nucleic Acids Res. 1994:22:4673-80.

27. Librado P, Rozas J. DnaSP v5: A software for comprehensive analysis of DNA polymorphism data. Bioinformatics. 2009;25:1451-2.

28. Tchigossou G, Djouaka R, Akoton R, Riveron JM, Irving H, Atoyebi S, et al. Molecular basis of permethrin and DDT resistance in an Anopheles funestus population from Benin. Parasit Vectors. 2018;11:602.

29. Tamura K, Peterson D, Peterson N, Stecher G, Nei M, Kumar S. MEGA5: molecular evolutionary genetics analysis using maximum likelihood, evolutionary distance, and maximum parsimony methods. Mol Biol Evol. 2011;28:2731-9.

30. Riveron JM, Ibrahim SS, Chanda E, Mzilahowa T, Cuamba N, Irving H, et al. The highly polymorphic CYP6M7 cytochrome P450 gene partners with the directionally selected CYP6P9a and CYP6P9b genes to expand the pyrethroid resistance front in the malaria vector Anopheles funestus in Africa. BMC Genomics. 2014;15:817.

31. Yang YH, Speed T. Design issues for CDNA microarray experiments. Nat Rev Genet. 2002;3:579-88.

32. Chuaqui R, Bonner R, Best C, Gillespie J, Flaig M, Hewitt S, et al. Postanalysis follow-up and validation of microarray experiments. Nat Genet. 2002;32:509-14.

33. Kostaropoulos I, Papadopoulos Al, Metaxakis A, Boukouvala E, Papadopoulou Mourkidou E. Glutathione S-transferase in the defence against pyrethroids in insects. Insect Biochem Mol Biol. 2001:31:313-9.

34. Vontas JG, Small GJ, Hemingway J. Glutathione S-transferases as antioxidant defence agents confer pyrethroid resistance in Nilaparvata lugens. Biochem J. 2001;357:65-72.

35. Lumjuan N, Rajatileka S, Changsom D, Wicheer J, Leelapat P, Prapanthadara LA, et al. The role of the Aedes aegypti Epsilon glutathione transferases is conferring resistance to DDT and pyrethroid insecticides. Insect Biochem Mol Biol. 2011:41:203-9.

36. Clayton JD, Cripps RM, Sparrow JC, Bullard B. Interaction of troponin-H and glutathione S-transferase-2 in the indirect flight muscles of Drosophila melanogaster. J Muscle Res Cell Motil. 1998;19:117-27.

37. Singh OP, Dykes $C L$, Lather $M$, Agrawal OP, AdakT. Knockdown resistance (kdr)-like mutations in the voltage-gated sodium channel of a malaria vector Anopheles stephensi and PCR assays for their detection. Malar J. 2011;10:59

38. Fang S-M. Insect glutathione S-transferase: a review of comparative genomic studies and response to xenobiotics. Bull Insectology. 2012;65:265-71.

39. Lumjuan N, Stevenson BJ, Prapanthadara LA, Somboon P, Brophy PM, Loftus BJ, et al. The Aedes aegypti glutathione transferase family. Insect Biochem Mol Biol. 2007:37:1026-35.

40. Yu Q, Lu C, Li B, Fang S, Zuo W, Dai F. Identification, genomic organization and expression pattern of glutathione -S -transferase in the silkworm, Bombyx mori. Insect Biochem Mol Biol. 2008;38:1158-64.

41. Wood OR, Hanrahan S, Coetzee M, Koekemoer LL, Brooke BD. Cuticle thickening associated with pyrethroid resistance in the major malaria vector Anopheles funestus. Parasit Vectors. 2010;3:67.

42. Yahouédo GA, Chandre F, Rossignol M, Ginibre C, Balabanidou V, Mendez NGA, et al. Contributions of cuticle permeability and enzyme detoxification to pyrethroid resistance in the major malaria vector Anopheles gambiae. Sci Rep. 2017;7:11091.

43. Nkya TE, Akhouayri I, Kisinza W, David JP. Impact of environment on mosquito response to pyrethroid insecticides: Facts, evidences and prospects. Insect Biochem Mol Biol. 2013:43:407-16.

\section{Publisher's Note}

Springer Nature remains neutral with regard to jurisdictional claims in published maps and institutional affiliations. 